\title{
Neighbours matter: A nation-wide small-area assessment of environmental inequality in Germany
}

\author{
Tobias Rüttenauer \\ University of Kaiserslautern \\ Erwin-Schrödinger-Str. 57 \\ D-67663 Kaiserslautern \\ Germany
}

CONTACT

ruettenauer@sowi.uni-kl.de

\section{Authors' preprint version. Please cite the final article:}

Rüttenauer, T. (2018). Neighbours matter: A nation-wide small-area assessment of environmental inequality in Germany. Social Science Research, 70, 198-211.

DOI: 10.1016/j.ssresearch.2017.11.009

\section{LAST EDITED}

November 2017

\begin{abstract}
This study investigates the presence of environmental inequality in Germany and analyses its spatial pattern on a very fine grained level. Using the 2011 German census and pollution measures of the E-PRTR, the study relies on nearly 100,000 one squared $\mathrm{km}$ census cells over Germany. SLX and community-fixed SLX models incorporate spatial spillover-effects into the analysis to account for the spatial distribution of socio-demographic characteristics. Results reveal that the share of minorities within a census cell indeed positively correlates with the exposure to industrial pollution. Furthermore, spatial spillover effects are highly relevant: the characteristics of the neighbouring spatial units matter in predicting the amount of pollution. Especially within urban areas, clusters of high minority neighbourhoods are affected by high levels of environmental pollution. This highlights the importance of spatial clustering processes in environmental inequality research.
\end{abstract}




\section{Introduction}

Environmental inequality research addresses the question of whether environmental pollution is unequally distributed across different groups of citizens. In the United States, a vast body of research has shown that ethnic minorities and socio-economically disadvantaged groups face a disproportionately high exposure to environmental pollution (e.g. Ash \& Fetter, 2004; Ash et al., 2013; Banzhaf \& Walsh, 2008; Been \& Gupta, 1997; Crowder \& Downey, 2010; Downey \& Hawkins, 2008; Downey et al., 2008; Mohai \& Saha, 2007; Pais et al., 2014; Pastor et al., 2001; Szasz \& Meuser, 2000). While the assessment of environmental inequality in some European countries has grown during the last years (e.g. Diekmann \& Meyer, 2010; Funderburg \& Laurian, 2015; Havard et al., 2009; Padilla et al., 2014; Richardson et al., 2010), empirical analyses in Germany are still scarce. Furthermore, the existing studies in Germany either use subjective measures of environmental pollution (Kohlhuber et al., 2006; Mielck, 2004) or focus on single regional areas (Kabisch \& Haase, 2014; Raddatz \& Mennis, 2013). Although this research has contributed greatly to the understanding of environmental inequality, Germany lacks a nation-wide assessment of environmental inequality that uses objective indicators for environmental pollution.

The present study addresses this gap in the literature by analysing the connection between the foreign-minority population and objectively measured industrial pollution. By connecting 2011 German census data with industrial facilities of the European Pollutant Release and Transfer Register (E-PRTR), the analyses build on an original dataset of 93,777 (1 km² sized) grid cells over Germany. Thus, the connection between the socio-demographic distribution and environmental pollution is evaluated on a very fine grained spatial level. The study uses the proportionate toxicity-weighted pollution from surrounding facilities as well as the proximity to the nearest facility as indicators for environmental pollution. Additionally, it incorporates housing indicators to test whether the connection between minority groups and pollution is mediated by housingrelated variables.

Furthermore, this paper extends the question regarding the presence of environmental inequality in Germany in two ways. First, spatial models (SLX) are used to test for the existence of spatial spillover effects. Using these models allows for separating the effects of the unit's characteristics itself and the effects stemming from neighbouring spatial units. Hence, this study explicitly models the spatial pattern of environmental inequality and tests whether neighbouring units matter in predicting environmental pollution. Second, it investigates whether the spatial spillover effects differ between rural and urban areas. Therefore, community-fixed effects SLX models are used to compare environmental inequality within urban and rural areas. This analysis contributes to the existing literature not only by assessing the presence of environmental inequality but also by investigating its spatial structure. The results highlight the importance of spatial spillover and clustering effects in environmental inequality research.

\section{Theoretical background}

Previous scholars have argued that environmental inequality may stem from two different processes: selective siting and selective migration. While the selective siting argument posits that hazardous facilities are disproportionately sited in minority neighbourhoods, the selective migration argument assumes that minority households may 
disproportionately migrate into polluted areas. ${ }^{1}$

The reason for selective siting may be twofold. First, areas holding a high minority share are expected to face lower housing costs (Downey, 2005; Farber, 1998; Saha \& Mohai, 2005; Wolverton, 2009, 2012). Second, minority groups may lack the political power to prevent the siting of new facilities (Hamilton, 1995; Mohai \& Saha, 2015a; Pastor et al., 2001). Both characteristics make high minority areas an attractive location for industrial facilities. However, the empirical results regarding the causal mechanisms are mixed. While some studies find a connection between minority share and the probability of receiving an industrial facility (Funderburg \& Laurian, 2015; Mohai \& Saha, 2015b; Pastor et al., 2001), others find none (Downey, 2005; Oakes et al., 1996) or only weak support (Been \& Gupta, 1997; Shaikh \& Loomis, 1999) for selective siting.

In contrast to the selective siting argument, the selective migration argument assumes that neighbourhood characteristics are not a predictor of facility siting. Instead, the argument works the other way round: neighbourhood pollution predicts neighbourhood characteristics. This means that minority households selectively move into polluted areas. Again, two mechanisms clarify this argument. First, lower housing prices in polluted areas make these areas more attractive for low income households and, thus, to minority households because of their lower socio-economic status (Been \& Gupta, 1997; Campbell et al., 2010; Downey, 2005; Crowder et al., 2011; Pais et al., 2014). This is called the 'racial income-inequality thesis', which will be tested indirectly in the analysis. Second, minority households may face significant discriminatory barriers on the housing market when trying to enter high quality neighbourhoods (Crowder et al., 2011, 2012; Pais et al., 2014). While previous research on the macro level failed to identify selective migration as a cause of environmental inequality (Been \& Gupta, 1997; Downey, 2005; Funderburg \& Laurian, 2015; Mohai \& Saha, 2015b; Oakes et al., 1996; Pastor et al., 2001; Shaikh \& Loomis, 1999), research on the household level found clear evidence for selective migration of minority households into polluted areas (Crowder \& Downey, 2010; Pais et al., 2014). Furthermore, those studies on the micro level conclude that socio-economic factors can only partly explain the racial gap in moving behaviour.

Although studies conducted in Germany did not aim to compare the causes of environmental inequality, they give important insights about the presence of environmental inequality. Kohlhuber et al. (2006) find non-German citizens to perceive a higher degree of exposure to noise and air pollution also when controlling for socio-economic indicators. In the same manner, Raddatz \& Mennis (2013) find the percentage of foreigners to be negatively correlated with the distance to the next industrial facility in the city of Hamburg, even when controlling for the percentage of welfare recipients. For the city of Berlin, Kabisch \& Haase (2014) identify a lower provision of urban green space in city districts with a higher minority share. In addition to the identification of general environmental inequality in Germany, the first two studies show that dissimilarities in the exposure to pollution between minority and majority groups cannot be explained solely by socio-economic variables. However, while the first study uses subjective measures of pollution, the latter concentrate on single German cities. Therefore, the present study is the first nation-wide assessment of environmental inequality that uses objective measures of pollution.

\footnotetext{
${ }^{1}$ Note that minorities in the United States are predominantly defined as ethnic minorities. In Germany, minorities stem mostly from recent migration processes, and are thus defined as foreign-minority and later operationalised as foreign population. Still, it is assumed that the same mechanism apply as discussed in the American literature.
} 


\section{Neighbours matter}

Following theoretical explanations as well as findings from previous research, we expect the percentage of minority members to be positively correlated with the exposure to environmental pollution and the proximity to the next industrial facility. However, this simple correlation does not take into account the spatial distribution of minority groups and environmental pollutants. Although the cross-sectional design of this study does not allow testing causal mechanisms that lead to environmental inequality, the theoretical explanations offer some predictions of the spatial patterns that are to be expected from these processes.

First, if selective siting causes the unequal distribution of environmental pollution over different households, we expect the broader neighbourhood to be a main driver of environmental pollution. In other words, when companies decide where to place a new facility, it is not a single neighbourhood that is decisive but rather whole clusters of neighbourhoods. If the theory of selective siting is correct, companies will place facilities where low-income or minority households cluster because lower housing prices and less political protest can be expected in those areas. Therefore, not only the minority share of a unit itself, but also the minority share of the broader neighbourhood is expected to be an important predictor of environmental pollution. Furthermore, existing industrial facilities may attract new industrial facilities due to attractive infrastructure opportunities (Ard, 2016; Elliott \& Frickel, 2013). This would reinforce the clustering of industrial facilities and minority neighbourhoods.

Second, if selective migration causes environmental inequality, the broader neighbourhood may be important as well. The argument of selective migration, as outlined above, only considers environmental quality as a decisive preference for a household's relocation. However, as shown theoretically by Schelling (1978) and confirmed by recent research (Clark \& Coulter, 2015; Crowder et al., 2011, 2012; Krysan et al., 2009; Rathelot \& Safi, 2014; Sager, 2012), minority and majority groups tend to segregate spatially because of similarity preferences, which means households prefer to have members of their own group within their neighbourhood. Thus, if households of minority groups tend to move into polluted areas because of affordable housing opportunities, they will attract even more members of the minority group while staving off majority-group households. Kim et al. (2014) show formally that the similarity preferences of households help to explain the observed disproportionate exposure of minority groups. As in the previous case of selective siting, minority households are expected to cluster around high pollution areas.

Again, it is important to note that it is impossible to distinguish between those processes - selective siting and selective migration - in a cross-sectional design. However, it is possible to test whether pollution correlates especially with high minority clusters by incorporating spatial spillover effects. More precisely, the present study will test if the minority share of neighbouring spatial units will influence the exposure to environmental pollution or, in other words, if neighbours matter. Additionally, housing market characteristics of the census tract and housing market characteristics of the neighbourhood are incorporated to investigate whether these characteristics can explain the correlation between minority share and environmental pollution.

Additionally, there might also be significant variation in the patterns of environmental inequality between different types of communities. As previous research has shown, urban and rural areas may face differences in segregation processes (Catney, 2016; Crowder et al., 2012; Sager, 2012) as well as in pollution patterns (Ard, 2015; Briggs et al., 2008). Therefore, patterns of environmental inequality may differ between 
urban and rural areas in two ways. First, the direct correlation between minority share and pollution may be stronger within metropolitan areas because these areas generally face higher segregation levels (Sager, 2012) and pollution may be more concentrated in these segregated areas. In line with this argument, results by Ard (2016) indicate that segregation is associated with increasing overall health risks from industrial pollution but also with additional health risks for minority neighbourhoods. Second, the spatial spillovers may be stronger in metropolitan areas. Previous research has shown that segregation between central and suburban districts within metropolitan areas (macro segregation) increased during the last decades (Lichter et al., 2015). This could indicate that the expected clustering effects may be stronger within urban areas.

On the other hand, segregation could also reduce environmental inequality. As Downey (2007) notes, minority succession processes may lead to the concentration of minority groups in city centres (or in other parts of the city) absolutely independent from the concentration of pollution sources. In contrast to the first argument, this second argument would result in a lower correlation between minority share and pollution within urban areas.

In sum, the present paper tests 1) if there is environmental inequality in Germany when using objective measures, 2) if neighbours matter in explaining the level of pollution and 3) if the patterns of environmental inequality differ between urban and rural areas.

\section{Data and methods}

\subsection{Data}

To answer these questions two different data sources are combined: demographic data of the 2011 German census and pollution reports of the European Pollutant Release and Transfer Register (E-PRTR) for 2011.

The German census (Statistische Ämter des Bundes und der Länder, 2015) provides information about the population on the basis of a one squared $\mathrm{km}$ grid. This grid divides Germany into 361,478 equally sized and distributed grid cells, of which 214,633 are populated by at least one household. Excluding grid cells with missing data (due to low numbers of inhabitants and confidentiality issues) leads to a final dataset of 93,777 grid cells. ${ }^{2}$ This final dataset still contains information of nearly 73 million inhabitants (90.94\% of the total German population). The 93,777 grid cells are defined as neighbourhoods in the current study, though they define no administrative or reallife boundaries of neighbourhoods, but just result from a random grid. This is an advantage for the present research as the grid boundaries itself should not be related to siting or clean-up decisions (because they are not meaningful for administrative authorities). On average, these one squared $\mathrm{km}$ sized neighbourhoods contain 778 inhabitants (median: 303 inhabitants) and thus, offer a very fine grained spatial level to assess the presence and the spatial patterns of environmental inequality.

The E-PRTR (European Commission, 2006) contains information about industrial facilities falling under one or more of the 65 E-PRTR industrial activities (European Commission, 2006, pp. 79-82), which exceed a pollutant specific threshold of emissions (European Commission, 2006, pp. 83-86). For 2011 the dataset contains a total of 4,971 facilities, of which 1,476 report industrial emissions to air, and 3,495 report

${ }^{2}$ When including all 201,101 non-missing units into the baseline model (containing only the minority share as explanatory variable), results similar to the presented baseline model M1 are obtained. 
waste management activities or emission to land and water. ${ }^{3}$ In sum, these facilities report nearly $1 \mathrm{~b}$ tonnes of emissions to air and nearly $90 \mathrm{~m}$ tonnes of processed waste. These pollution data are matched with the grid cells of the German census by using the georeferenced location of the facilities.

\subsection{Variables}

To measure the exposure to environmental pollution, two different indicators were constructed. The main indicator is the amount of toxicity-weighted industrial air pollution, while the proximity to the nearest industrial facility is used as a complementary indicator to examine the robustness of the results.

To compute the air pollution for each census grid cell, a $2 \mathrm{~km}$ buffer around each facility location was constructed and the emissions were allocated to the census cells proportional to the overlap of the $2 \mathrm{~km}$ buffer and the census cell boundaries. This method is similar to the method used by Banzhaf \& Walsh (2008) and addresses the problem that facilities may be sited at the edges of spatial units (Mohai \& Saha, 2006, 2007). In a second step, the aggregated air pollution was calculated as the toxicityweighted sum of all air pollutants, which were allocated to each census grid cell in the first step. For weighting, the inhalation toxicity weights of the United States Environmental Protection Agency's (EPA) Risk Screening Environmental Indicators (RSEI) database were used (Environmental Protection Agency, 2015). The resulting measure is similar to the hazard-based results in the RSEI data and provides an estimate of the amount of industrial emissions weighted by each pollutant's potential for long-term health risks. This includes pollutants like chlorinated substances, heavy metals, and other gases and organic substances (like ammonia, benzene, or fluorine), while excluding greenhouse gases (like $\mathrm{CO}_{2}, \mathrm{NO}_{\mathrm{x}}, \mathrm{PM}_{10}, \mathrm{SO}_{\mathrm{x}}$ ), which are not classified as causing chronic human health impacts (e.g. cancer). ${ }^{4}$ In a final step, the natural logarithm of this proportionate amount of toxicity-weighted air pollution was computed to take the right skewness into account.

This measure of exposure to pollution (as used by Banzhaf \& Walsh, 2008) is superior to the widely used unit-coincidence methods (for a discussion see e.g. Mohai \& Saha, 2007) or hazard-proximity measures (e.g. Crowder \& Downey, 2010), but less sophisticated than the RSEI scores used in recent studies in the United States (e.g. Ash et al., 2013; Ard, 2015). In contrast to the United States RSEI, the European EPRTR does not offer exposure estimates based on plume models, accounting for stack high, wind direction, wind speed, and resulting surrogate dose of emissions. Though the current study uses the same air pollutants and toxicity-weights as RSEI data, it can only use a less accurate approximation of actual exposure to pollution as provided by the RSEI.

The second measure, the proximity to the nearest facility, is calculated as the inverted Euclidean distance between the centre of each census grid cell and the facility located nearest to the grid cell. In contrast to the measure of air pollution (including 1,476 facilities), the second measure also includes facilities reporting waste management activities or emission to land and water (4,971 facilities). The proximity to industrial facilities does not aim for measuring any physical health impacts, but rat-

\footnotetext{
${ }^{3}$ Note that the E-PRTR relies on self-reported emissions, which is prone to reporting biases. However, complementary analyses using the E-PRTR reports from 2010 to 2012 and 3-years average emissions yield nearly identical results.

${ }^{4}$ Additional analyses not using toxicity weights but aggregating over all emission (including greenhouse gases) lead to similar conclusions but less conservative point estimates (not shown).
} 
her represents an indicator of reduced neighbourhood quality (due to potential noise, visibility of industrial facilities, or odour). Thus, the two measures, toxicity weighted air pollution and proximity to the nearest facility, offer the possibility to evaluate the presence of environmental inequality by using two distinct dimensions of exposure to environmental pollution. While the amount of toxicity weighted pollution provides a measure related to health risks, the proximity should mostly capture disadvantages due to visibility or odour nuisances of close facilities. However, both measures can only provide an approximation of exposure to environmental pollution (though it is the best possible approximation based on the available data in Europe).

The explanatory variables stem from the 2011 census data. Minority share is available as the percentage of foreigners, which is defined as the proportion of inhabitants without a German citizenship. Additional control variables are included to test if the correlation between minority share and pollution can be explained due to differences in socio-economic characteristics. Most importantly, the living space per inhabitant can be seen as a proxy of socio-economic status. ${ }^{5}$ Second, the percentage of vacant housing approximates the housing market conditions, as a higher percentage of vacant housing should correlate with less demand for housing and, therefore, lower housing prices. To investigate the differences between urban and rural areas, a dichotomous variable is constructed that takes the value one for all grid cells that are located within a community with at least 100,000 inhabitants, and zero otherwise. Furthermore, the number of inhabitants (which equals population density because of similar census cell sizes) as well as the percentage of inhabitants aged 65 or older are included as controls.

\section{3. $\quad$ Method}

In a first step, a simple OLS model is used to investigate the connection between minority share and pollution. However, the simple OLS model is not able to take the spatial nature of the data into account. Moran's I test confirms that the non-spatial OLS model exhibits a highly significant spatial residual correlation, indicating that observations are not independent. As shown by Pace \& LeSage (2010), spatial autocorrelation in the dependent variable $\operatorname{cov}(\boldsymbol{W} \boldsymbol{y}, \boldsymbol{y}) \neq 0$ does not only lead to erroneous inferences, but also to biased point estimates in case of $\operatorname{cov}(\boldsymbol{W} \boldsymbol{x}, \boldsymbol{x}) \neq 0$, where $\boldsymbol{W}$ specifies the $N \times N$ spatial weights matrix (all $w_{i j}>0$ for neighbouring $i$ and $j \neq i$, and $w_{i j}=0$ otherwise), $\boldsymbol{y}$ the $N \times 1$ vector of the dependent variable and $\boldsymbol{x}$ the $N \times 1$ vector of the independent variable. In other words, if the explanatory variable $x_{i}$ of unit $i$ is correlated with the explanatory variable $x_{j}$ and the outcome variable $y_{j}$ of the neighbouring unit $j$, OLS estimates of $\beta_{x}$ suffer from omitted variable bias.

Several model specifications exist that incorporate the spatial dependence of the data by including spatial lags of the dependent variable (SAR), a spatially weighted error term (SEM), or both (e.g. LeSage \& Pace, 2009; Ward \& Gleditsch, 2008). However, the SEM does not estimate spatial spillover effects, which are of interest for the research question at hand. Though the SAR does provide estimates of direct and spillover effects, those are global spillover processes as a change in the explanatory variable of one observation affects all other observations, which is not intuitively interpretable (for a detailed explanation see e.g. LeSage, 2014). In addition, the ratio between direct and spillover effects is fixed for all parameters of the covariates as a

\footnotetext{
${ }^{5}$ Note that this is the best available proxy for wealth at this fine-grained spatial level. Though wealthy people might move to small flats in inner cities (e.g. to reduce commuting distance), this problems seems less severe in the present study as the analysis simultaneously controls for population density.
} 
SAR specification estimates only one autoregressive parameter. Thus, the flexible SLX model is more suitable for the research question of this study (Elhorst, 2014; Halleck Vega \& Elhorst, 2015). This model allows testing whether 'neighbours matter' or more precisely, whether the minority share of neighbouring units spills over and affects the level of pollution in the focal spatial unit. Furthermore, the SLX model is attractive due its simplicity as the coefficients can be interpreted directly (in contrast to the SAR coefficients).

The SLX model is specified as

$$
\boldsymbol{y}=\alpha \boldsymbol{\iota}+\boldsymbol{X} \boldsymbol{\beta}+\boldsymbol{W} \boldsymbol{X} \boldsymbol{\theta}+\boldsymbol{\epsilon},
$$

where $\boldsymbol{W}$ and $\boldsymbol{y}$ are defined as above, $\boldsymbol{\iota}$ is a $N \times 1$ vector of ones, $\alpha$ the model intercept, $\boldsymbol{X}$ a $N \times K$ matrix of $K$ covariates, and $\boldsymbol{\epsilon}$ a $N \times 1$ vector of residuals (for $i=1, \ldots, N$ units). $\boldsymbol{\beta}$ and $\boldsymbol{\theta}$ are $K \times 1$ parameter vectors: while $\boldsymbol{\beta}$ contains the parameters of the direct effect estimates, $\boldsymbol{\theta}$ contains the parameters of the local spatial spillover effects between neighbouring units. These spillover effects can be interpreted as the average effects of the focal unit's neighbours. In the present study, the weights matrix is defined as contiguity (Queens) neighbours matrix, which includes all units as neighbours sharing at least one common border. As this would drop all observations without a direct neighbour (otherwise $w_{i j} x_{j}$ would spuriously equal zero), the nearest neighbouring unit was imputed for all units without a direct neighbour. In the final sample this affects $6.8 \%$ of the units. The outlined modelling strategy leads to an average number of 3.6 neighbours per unit (ranging from 1 to 8 neighbours). Alternative measures are considered in the discussion section.

Two different modelling strategies are used to investigate the correlation between minority share and pollution. The first strategy uses an overall SLX model (as defined above), thus investigating if the minority share in a census grid cell is correlated with pollution in a nation-wide comparison. This might, however, result from the fact that the average minority share is higher in cities or areas where also pollution is high (e.g. the mid-western region of Germany), thereby only capturing regional level-differences. Thus, the second strategy uses community-fixed effects SLX models. This strategy controls for the community-constant differences between 4,518 communities (e.g. the community's share of minorities or level of pollution) and, additionally, 'differences out' unobservable differences between the communities. Consequently, those fixed effects models investigate whether census grid cells with a high minority share are affected by a disproportionately high pollution within the communities (compared to census grid cells within the same community), independent of general regional differences. All models were estimated using $R$ 's package spdep (Bivand \& Piras, 2015).

\section{Results}

Table 1 shows the descriptive statistics of the used variables separated by rural and urban areas. The table includes the distance instead of the proximity to the nearest facility because it is intuitively interpretable (in contrast to its inverse). Industrial air pollution tends to be higher, and the average distance to the nearest industrial or waste management facility tends to be lower in urban areas. This indicates a generally higher exposure to industrial pollution in urban areas. At the same time, the percentage of minority inhabitants living within each census cell is nearly three times higher in urban areas. These summary statistics clearly indicate that it is important to account 
Table 1. Descriptive statistics

\begin{tabular}{|c|c|c|c|c|c|c|}
\hline \multirow[b]{2}{*}{ Variable } & \multicolumn{2}{|c|}{ Rural } & \multicolumn{2}{|c|}{ Urban } & \multicolumn{2}{|c|}{ Overall } \\
\hline & Mean & $\mathrm{SD}$ & Mean & $\mathrm{SD}$ & Mean & $\mathrm{SD}$ \\
\hline Air pollution (ln kg) & 0.54 & $(2.59)$ & 1.79 & $(5.01)$ & 0.66 & $(2.93)$ \\
\hline $\begin{array}{l}\text { Distance to nearest facility } \\
(\mathrm{km})\end{array}$ & 7.82 & $(4.57)$ & 3.21 & $(1.81)$ & 7.37 & $(4.59)$ \\
\hline$\%$ Foreigners & 3.02 & $(4.66)$ & 9.00 & $(8.43)$ & 3.59 & $(5.44)$ \\
\hline Population & 577.58 & $(835.71)$ & 2649.91 & $(2887.97)$ & 777.82 & $(1345.95)$ \\
\hline$\% 65$ and older & 19.56 & $(8.74)$ & 20.57 & $(7.44)$ & 19.65 & $(8.63)$ \\
\hline$\%$ Vacant housing & 3.46 & $(4.12)$ & 3.50 & $(3.54)$ & 3.46 & $(4.07)$ \\
\hline Living space & 44.93 & $(6.66)$ & 41.74 & $(5.95)$ & 44.63 & (6.66) \\
\hline $\mathrm{N}$ & \multicolumn{2}{|c|}{84716} & \multicolumn{2}{|c|}{9061} & \multicolumn{2}{|c|}{93777} \\
\hline
\end{tabular}
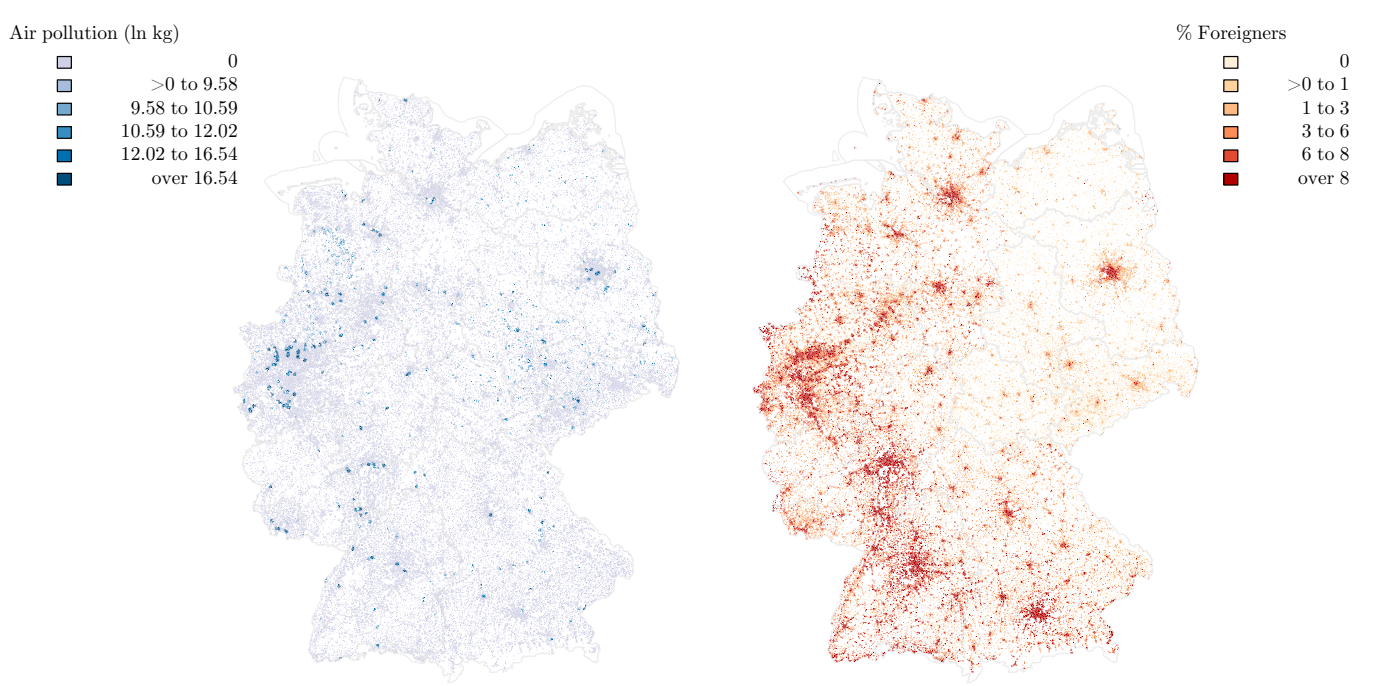

Figure 1. Spatial distribution of air pollution and minority share in Germany
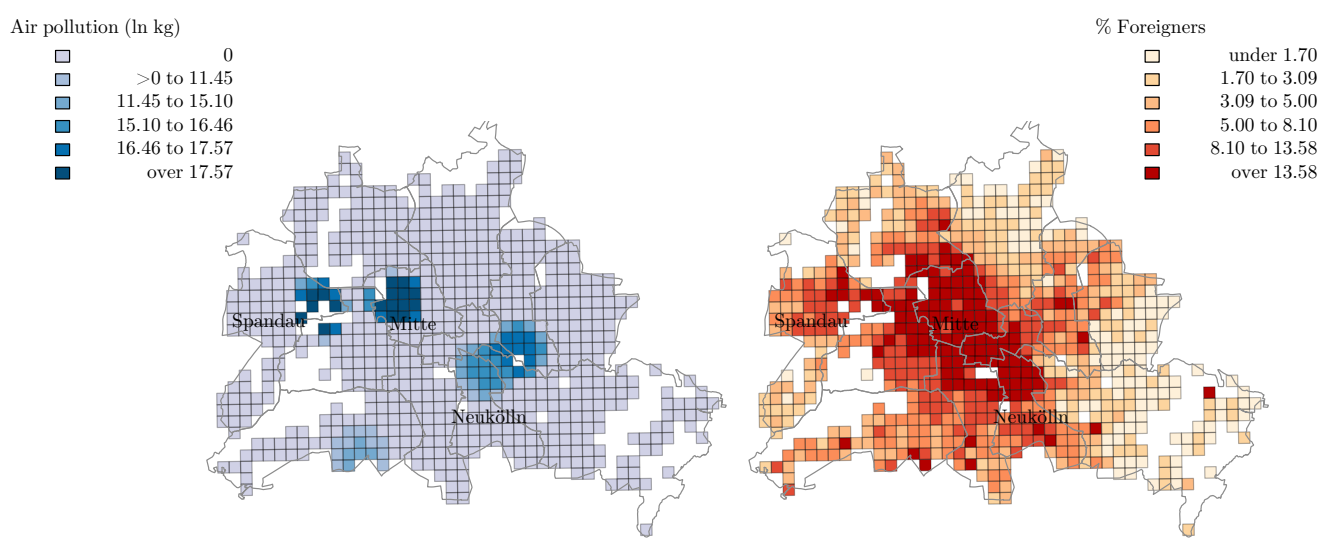

Figure 2. Spatial distribution of air pollution and minority share in Berlin 
for the differences between urban and rural areas when analysing the patterns of environmental inequality.

Figure 1 illustrates the spatial distribution of air pollution and minority share graphically. Analogue to the descriptive statistics, Figure 1 shows that highly polluted census cells as well as neighbourhoods with a high percentage of minority inhabitants cluster around urban areas. Particularly the mid-western part of Germany holds a high pollution and census cells with a high minority share. Regarding the remaining parts of Germany, high levels of minority inhabitants and pollution (to a lower extent) occur especially around the metropolitan areas. The spatial clustering of the variables of interest further supports the finding of high spatial correlation between the units of observations and illustrates graphically that the individual census cells cannot be handled as if they were independent of each other. To take the city of Berlin as an example (Figure 2), this finding does not only apply for the whole country but also for the distribution within cities. The Berlin district 'Mitte', for example, is characterised by a high percentage of minority inhabitants and is also affected by high pollution. Another interesting pattern can be found within the districts of 'Neukölln' and 'Spandau': within the districts, those cells with a high share of minorities are affected by the highest level of pollution. These geographical patterns offer a first sign for a positive correlation between minority share and pollution in Germany as a whole but also within metropolitan areas. Very similar patterns can be seen when looking at the proximity to the nearest industrial facility (as shown in Figures A1 and A2 in the appendix).

To test whether census cells with a higher minority share face a higher exposure to industrial pollution, Table 2 presents the results of the multiple regression models, regressing the industrial air pollution on the percentage of foreigners and further controls. All variables (except dichotomous variables) are standardised, allowing for the interpretation of the coefficients' magnitude in terms of standard deviations.

Model M1 represents the baseline model without any control variables or spatially lagged explanatory variables. The model confirms the impression of the previous figures: the percentage of minority inhabitants within a census cell is positively correlated with air pollution. Thus, model M1 confirms the presence of environmental inequality in Germany. Model M2 indicates, however, that the effect magnitude of model M1 is likely to be biased. When incorporating the spatially lagged minority share - meaning the average minority share in the neighbouring census cells - the model yields a much weaker direct correlation between minority share and air pollution. A big proportion of the effect in model M1 seems to be driven by the spatial correlation between neighbouring units. Furthermore, it confirms the hypothesis that neighbours matter. The level of pollution is not only correlated with the minority share of the focal unit but also with the minority share of neighbouring units.

When comparing the effect magnitudes of direct and spillover effects, it is important to keep in mind that the spatially lagged minority share represents the average minority share of the neighbours. This means that an increase in the minority share in all neighbouring units together (which are 3.6 neighbours on average) by one standard deviation is correlated with a 0.11 standard deviations higher pollution in the focal unit. Consequently, one could say that the characteristics of the surrounding area matter more than the characteristics of the census cell itself. However, this does not mean that a higher minority share in just one neighbouring unit has a stronger impact than the unit specific characteristics themselves.

The results presented so far support the hypothesis that high minority neighbourhoods experience a disproportionate high exposure to environmental pollution and 
Table 2. OLS and SLX estimates. Dependent variable: industrial air pollution

\begin{tabular}{|c|c|c|c|c|}
\hline & \multirow{2}{*}{$\begin{array}{c}\text { OLS } \\
\text { M1 }\end{array}$} & \multicolumn{3}{|c|}{ SLX } \\
\hline & & M2 & M3 & M4 \\
\hline (Intercept) & $\begin{array}{c}0.000 \\
(0.003)\end{array}$ & $\begin{array}{r}-0.003 \\
(0.003)\end{array}$ & $\begin{array}{c}-0.027^{* * *} \\
(0.003)\end{array}$ & $\begin{array}{c}-0.027^{* * *} \\
(0.003)\end{array}$ \\
\hline$\%$ Foreigners & $\begin{array}{l}0.120^{* * *} \\
(0.003)\end{array}$ & $\begin{array}{l}0.054^{* * *} \\
(0.005)\end{array}$ & $\begin{array}{l}0.039^{* * *} \\
(0.005)\end{array}$ & $\begin{array}{c}0.012^{*} \\
(0.005)\end{array}$ \\
\hline $\mathrm{W}[\%$ Foreigners $]$ & & $\begin{array}{l}0.113^{* * *} \\
(0.005)\end{array}$ & $\begin{array}{l}0.084^{* * *} \\
(0.006)\end{array}$ & $\begin{array}{c}0.014^{*} \\
(0.007)\end{array}$ \\
\hline Population & & & $\begin{array}{c}-0.006 \\
(0.005)\end{array}$ & $\begin{array}{c}0.009 \\
(0.007)\end{array}$ \\
\hline W [Population] & & & $\begin{array}{c}0.002 \\
(0.007)\end{array}$ & $\begin{array}{l}0.064^{* * *} \\
(0.010)\end{array}$ \\
\hline$\% 65$ and older & & & $\begin{array}{c}0.003 \\
(0.003)\end{array}$ & $\begin{array}{c}0.003 \\
(0.003)\end{array}$ \\
\hline $\mathrm{W}[\% 65$ and older $]$ & & & $\begin{array}{c}0.006 \\
(0.005)\end{array}$ & $\begin{array}{c}0.009 \\
(0.005)\end{array}$ \\
\hline$\%$ Vacant housing & & & $\begin{array}{l}0.009^{* *} \\
(0.003)\end{array}$ & $\begin{array}{c}0.003 \\
(0.004)\end{array}$ \\
\hline $\mathrm{W}[\%$ Vacant housing $]$ & & & $\begin{array}{c}0.010^{*} \\
(0.005)\end{array}$ & $\begin{array}{r}-0.003 \\
(0.005)\end{array}$ \\
\hline Living space & & & $\begin{array}{c}-0.034^{* * *} \\
(0.004)\end{array}$ & $\begin{array}{c}-0.027^{* * *} \\
(0.004)\end{array}$ \\
\hline W [Living space] & & & $\begin{array}{c}-0.075^{* * *} \\
(0.005)\end{array}$ & $\begin{array}{c}-0.055^{* * *} \\
(0.005)\end{array}$ \\
\hline Urban & & & $\begin{array}{l}0.245^{* * *} \\
(0.013)\end{array}$ & $\begin{array}{l}0.117^{* * *} \\
(0.016)\end{array}$ \\
\hline Urban $\times \%$ Foreigners & & & & $\begin{array}{l}0.055^{* * *} \\
(0.013)\end{array}$ \\
\hline Urban $\times \mathrm{W}[\%$ Foreigners $]$ & & & & $\begin{array}{l}0.290^{* * *} \\
(0.017)\end{array}$ \\
\hline$R^{2}$ & 0.014 & 0.019 & 0.032 & 0.044 \\
\hline Adj. $R^{2}$ & 0.014 & 0.019 & 0.031 & 0.044 \\
\hline $\mathrm{N}$ & 93777 & 93777 & 93777 & 93777 \\
\hline
\end{tabular}

${ }^{* * *} p<0.001,{ }^{* *} p<0.01,{ }^{*} p<0.05$. Standardised coefficients. Standard errors in parentheses. W is specified as contiguity neighbours weights matrix. Model M4 interacts all covariates with the urban dummy (interaction with controls not shown).

that neighbours matter by influencing the pollution level. However, the models do not control if the correlation between minority share and pollution is a consequence of socio-economic or housing-related characteristics. Model M3 adds several control variables, all modelled as direct and spillover effects. Living space per inhabitant and the share of vacant housing show a significant and theoretically plausible effect on the amount of pollution. More importantly, these area- and housing-related control variables explain a considerable proportion of the minority effect. The magnitude of the direct as well as the spillover effect of the minority share is reduced by more than $25 \%$. However, supplementary models (not shown) reveal that the housing-related variables do a rather poor job in explaining the disproportionate burden of neighbourhoods facing a high minority share. The reduction of the minority effect occurs mainly due to controlling for urban areas (or if excluded due to population density). Thus, a significant proportion of the correlation between minority share and pollution found in model M2 can be ascribed to the fact that minority households cluster in urban areas, which tend to suffer from higher levels of industrial air pollution. The argument that disproportionate pollution in high minority areas stems from cheaper housing opportunities cannot be supported by the analysis. 
Table 3. Community-fixed effects estimates. Dependent variable: industrial air pollution

\begin{tabular}{|c|c|c|c|c|}
\hline & Overall & Urban & Rural & Diff \\
\hline & M5 & M6 & M7 & (M6-M7) \\
\hline \multirow[t]{2}{*}{$\%$ Foreigners } & $0.062^{* * *}$ & $0.076^{* * *}$ & $0.035^{* * *}$ & $0.041^{*}$ \\
\hline & $(0.009)$ & $(0.016)$ & $(0.007)$ & $(0.017)$ \\
\hline \multirow[t]{2}{*}{ W [\% Foreigners $]$} & $0.163^{* * *}$ & $0.391^{* * *}$ & $0.077^{* * *}$ & $0.315^{* * *}$ \\
\hline & $(0.025)$ & $(0.070)$ & $(0.015)$ & $(0.071)$ \\
\hline \multirow[t]{2}{*}{ Population } & -0.010 & -0.011 & -0.008 & -0.002 \\
\hline & $(0.007)$ & $(0.009)$ & $(0.006)$ & $(0.011)$ \\
\hline \multirow[t]{2}{*}{ W [Population] } & -0.039 & $-0.124^{* * *}$ & -0.023 & $-0.100^{* *}$ \\
\hline & $(0.023)$ & $(0.030)$ & $(0.017)$ & $(0.034)$ \\
\hline \multirow[t]{2}{*}{$\% 65$ and older } & -0.005 & -0.001 & 0.000 & 0.000 \\
\hline & $(0.004)$ & $(0.017)$ & $(0.003)$ & $(0.017)$ \\
\hline \multirow[t]{2}{*}{$\mathrm{W}$ [\% 65 and older $]$} & -0.009 & -0.101 & 0.004 & -0.105 \\
\hline & $(0.007)$ & $(0.072)$ & $(0.005)$ & $(0.072)$ \\
\hline \multirow[t]{2}{*}{$\%$ Vacant housing } & $0.014^{* *}$ & 0.035 & $0.012^{* *}$ & 0.023 \\
\hline & $(0.005)$ & $(0.027)$ & $(0.004)$ & $(0.027)$ \\
\hline \multirow[t]{2}{*}{$\mathrm{W}[\%$ Vacant housing] } & $0.021^{*}$ & 0.087 & $0.020^{* *}$ & 0.068 \\
\hline & $(0.008)$ & $(0.092)$ & $(0.007)$ & $(0.093)$ \\
\hline \multirow[t]{2}{*}{ Living space } & $-0.012^{* *}$ & 0.014 & $-0.008^{*}$ & 0.022 \\
\hline & $(0.004)$ & $(0.022)$ & $(0.003)$ & $(0.022)$ \\
\hline \multirow[t]{2}{*}{ W [Living space] } & $-0.036^{* * *}$ & $-0.161^{*}$ & $-0.022^{* * *}$ & $-0.139^{*}$ \\
\hline & $(0.007)$ & $(0.070)$ & $(0.006)$ & $(0.070)$ \\
\hline$R^{2}$ & 0.018 & 0.076 & 0.005 & \\
\hline Adj. $R^{2}$ & -0.031 & 0.067 & -0.050 & \\
\hline $\mathrm{N}$ & 93777 & 9061 & 84716 & \\
\hline
\end{tabular}

Model M4 further investigates if the patterns of environmental inequality significantly differ between urban and rural areas. Note that all covariates are interacted with the urban dummy in model M4, as all processes may differ in urban areas (control interactions are not shown). Both interaction terms are significant and show that the direct as well as the spillover correlations between minority share and pollution are higher in urban areas. While the main effect of the urban dummy shows that people in general experience higher levels of pollution in urban areas, the interaction confirms an additional burden for minorities in urban areas. Comparing main and interacted effect indicates that the magnitude of the disadvantage results mainly from disadvantages in urban areas. Another interesting finding is that the difference in spillover effects is much stronger than the difference in direct effects. While the direct effect in urban areas is approximately six times as strong as in rural areas, the spillover effect is more than twenty times higher in urban areas. This indicates that neighbours matter especially in urban areas. Particularly in urban areas, pollution is correlated with clusters of high minority areas. This holds true even when accounting for the higher average number of neighbours in urban (5.87) than in rural (3.29) areas.

However, the results presented so far do not control for regional level-differences over Germany. Community-specific unobservables may bias the results. This might be especially problematic when comparing rural and urban areas. Therefore, Table 3 presents results from community-fixed effects models. These models control for the differences between 4,518 German communities and use only the 'within-community variance' to estimate the effects, while conditioning for all community-constant characteristics. For ease of interpretation an overall model as well as two models separately for urban and 
rural areas are estimated. The fourth column of Table 3 additionally presents a test for differences between urban and rural areas. These differences were computed by interacting all covariates in the overall model (M5) with the urban dummy.

First of all, model M5 estimates the within-community environmental inequality for all communities taken together. It turns out that the extent of environmental inequality is even stronger within communities than it is in a country-wide comparison (comparing M3 and M5). This finding is in line with results from the American context, where environmental inequality is found to be stronger within than between cities (Ash \& Fetter, 2004). Again, results support the hypothesis that neighbours matter. Also within communities, clusters of high minority neighbourhoods correlate significantly and positively with pollution. Additionally, the minority share is by far the strongest predictor of environmental pollution, though the models include controls for the share of vacant housing and living space per inhabitant, which should be more important if the socio-economic disadvantages of minority groups and resulting preferences for cheap housing are responsible for the higher exposure to environmental pollution.

Models M6 and M7 compare whether the patterns of environmental inequality differ between urban and rural areas. A first interesting finding is that population density of the surrounding area is a significant predictor of pollution only in urban areas, whereas the percentage of vacant housing correlates with pollution only in rural areas. In both urban and rural areas, pollution is significantly lower in areas with higher living space per inhabitant, though the direct effect is non-significant for urban areas. Regarding the minority share, the direct effect in urban areas is twice as strong as in rural areas. Furthermore, there are highly significant and strong differences in the spillover effects. The effect of the minority share spilling over from neighbouring units is more than four times higher within urban than within rural areas. Even when taking into account that observations in urban areas have on average 5.87 neighbours, the spatial spillover effect from a single neighbouring unit is nearly as strong in its magnitude as the effect of the focal unit's minority share itself. According to M6, a one-unit change in a single neighbouring cell has only a slightly lower impact $(0.391 / 5.87=0.067)$ than a one-unit change of the focal unit's minority share in urban areas (0.076). If all neighbours increased their minority share simultaneously, this would lead to an effect that is more than four times higher than the effect of an increase in the unit's own minority share.

In sum, the analyses reveal: 1) the disadvantage of minority neighbourhoods is stronger within urban areas and 2) this stems mostly from the fact that neighbours matter especially in urban areas. In general, results confirm that neighbours matter: industrial air pollution tends to be especially high in areas where high proportions of foreign inhabitants agglomerate.

\section{Discussion}

Though the theoretical predictions are supported by the results, there remain three critical issues regarding the presented models. First, although the models account for the covariance between $\boldsymbol{y}$ and $\boldsymbol{W} \boldsymbol{X}$, there still remains spatial autocorrelation in the residuals, which might result from spatially clustered unobservables that influence $\boldsymbol{y}$ and $\boldsymbol{X}$. Second, the conclusions, especially regarding the spatial spillover effects, might depend on the specification of the neighbourhoods weights matrix $\boldsymbol{W}$ and third, all analyses rely on toxicity-weighted air pollution from industrial facilities as an indicator for the exposure to environmental pollution. Therefore, these issues are addressed in the following paragraphs. 
To reduce the remaining spatial autocorrelation of residuals, a spatial Durbin model was estimated. The Durbin model, additionally, includes the spatially lagged dependent variable $\boldsymbol{W} \boldsymbol{y}$ on the right-hand side of the equation (e.g. LeSage \& Pace, 2009). This method reduces the spatial correlation of the residuals dramatically. Regarding the effect magnitudes, the spatial Durbin models yield similar direct but slightly higher spillover effects. ${ }^{6}$ This applies to the overall as well as the fixed effects Durbin model. Additionally, overall and fixed-effects Durbin models confirm that direct and spillover effects are significantly stronger in urban areas. In sum, the spatial Durbin models offer very similar results to the SLX models, while reducing the remaining residual autocorrelation.

Regarding the specification of the neighbourhood weights matrix, additional models were estimated with alternative specifications. When excluding cases without direct neighbours instead of imputing these connections, nearly identical results are obtained. When replacing the weights matrix by a 10 nearest neighbours matrix (while weighting the neighbours by inverse distance), direct effect magnitudes decrease while the spillover effects increase. However, the main story does not change. Another model specification includes first as well as second order neighbours separately (two different weights matrices). These models produce nearly identical direct effects but slightly smaller spillover effects for the first order neighbours. Interestingly, also the second order neighbours produce effects comparable to first order neighbours with particularly strong impacts in urban areas. Combining first and second order effects, these models estimate an even stronger spillover effect from neighbouring units. This further supports the story that neighbours matter: even the neighbours of the neighbours play a role in determining the level of pollution. All estimated alternatives also support the findings from the community-fixed effects models and the different patterns between urban and rural communities.

To ensure that the conclusions do not depend on the measure of exposure to environmental pollution, Tables A1 and A2 in the Appendix present the analyses of the results section with an alternative measure, the proximity to the nearest facility. In contrast to the first indicator, this measure additionally includes waste management facilities (like landfill sites). These analyses basically confirm the previous results. Census grid cells with a high minority share are located closer to industrial facilities and, again, neighbours matter: a high minority share of neighbouring units is associated with closer industrial facilities. Though the relative effect magnitude of the spillover effects compared to the direct effects is lower when using the proximity, these analyses confirm that the total effect of neighbouring units is stronger. Furthermore, the results confirm the conclusion regarding the area differences. The correlation between minority share and proximity to industrial facilities is stronger in urban areas, especially regarding the spatial spillover effects. Hence, neighbourhoods with a high minority share and neighbourhoods lying in an area with a high minority share are not only exposed to a higher amount of air pollution but are also located closer to industrial and waste management facilities. However, it must be noted that both measures only use indicators of industrial pollution and do not account for other sources of pollution like traffic.

\footnotetext{
${ }^{6}$ Note that the impacts in a Durbin model depend on the weights matrix and differ from the model's coefficients. I refer to the average direct and indirect effects over all units here (for more information see e.g. Halleck Vega \& Elhorst, 2015; LeSage \& Pace, 2009).
} 


\section{Conclusion}

Although environmental inequality has gained increasing interest in Europe, this is the first nation-wide wide assessment of environmental inequality in Germany that uses objectively measured pollution. Furthermore, the present study includes the spatial nature of environmental inequality patterns by using innovative spatial methods and including the characteristics of neighbouring units. This seems to be important as the theoretical mechanisms of environmental inequality concern not only single units but rather spatial clusters. In sum, the analyses yield three important results.

First, there is a considerably high correlation between the minority share and exposure to environmental pollution. Not only in a nation-wide comparison, but also within communities, minorities experience a higher exposure to environmental pollution. This means that minorities live in more polluted areas in Germany and in more polluted neighbourhoods within communities. Housing-related control variables do a poor job in explaining the correlation between minority share and pollution, indicating that the 'racial income-inequality thesis' finds no support. It rather indicates that the high exposure of minorities does not mainly stem from their low socio-economic status and the resulting need for low-cost housing. However, to adequately confirm this finding, panel data or natural experiments are needed to account for other non-observable confounders. With certainty, it can only be stated that neighbourhoods and areas with a high level of minorities are exposed to disproportionately high levels of pollution.

Second, neighbours matter, which means that neighbourhoods that are located within clusters of high minority neighbourhoods face a higher level of pollution, independent of their own characteristics. Thus, processes of spatial clustering seem to play an important role in shaping patterns of environmental inequality. One explanation could be that regions where minorities agglomerate offer attractive sites for industrial facilities as the probability of resistance declines with distance rather than boundaries. Another explanation could be that segregation of minorities around industrial facilities contributes to their disproportionate exposure to pollution. In combination with further attraction of minority households due to similarity preferences, this could induce a self-reinforcing processes leading to a clustering of minorities around industrial facilities. This is especially interesting as results from the United Stated (Downey, 2007) rather indicate that segregation patterns do not play a crucial role in determining the extent of environmental inequality. If this also applies to Germany, then why do we observe these clustering processes? To answer this question empirically, further research should have a more detailed look at the spatial patterns of environmental inequality. Especially in a time-series framework this could lead to new insights regarding the causes or structural conditions generating the disproportionate exposure of minority households to industrial pollution.

Third, the correlation between the minority share and environmental pollution is stronger within urban than within rural areas. Especially the spatial spillover effects stemming from neighbouring units are much stronger within urban communities. Urban infrastructures, the level of segregation, or urban housing opportunities may foster the extent of environmental inequality. On the one hand, minorities might be less clustered or segregated in rural areas, which prevents companies from selectively siting facilities close to minorities. Spatial restriction in urban areas, in contrast, could 'force' companies to place facilities closer to inhabitants, which might then disproportionately affect minorities. On the other hand, rural areas exhibit a lower population density and more relaxed housing markets, which might provide better opportunities to 'escape' polluted areas. This is also supported by the finding that higher vacancy 
rates are correlated with pollution within rural areas (but not within urban areas): people seem to leave polluted neighbourhoods in rural areas. Especially minority households might, in turn, profit from those relaxed housing situations, leading to lower barriers regarding discriminating behaviour as well as price pressure.

In sum, the present study offers a first assessment of environmental inequality in Germany using objective measures of air pollution, but also highlights the importance of spatial processes associated with environmental inequality. However, the results also open new issues for further research. This study estimates the exposure to environmental pollution by proportionately allocating the toxicity-weighted emissions of facilities to surrounding neighbourhoods. Though this is an improvement over other studies in Germany using subjective measures, it is far behind the accuracy provided by EPA's RSEI in the United States. Further effort should be undertaken to improve the data quality in Europe, including advanced models based on estimated surrogate doses of exposure as it is done by the RSEI. This would not only improve the quality of environmental inequality research in Europe but also offer the opportunity to conduct comparative studies between different countries, thereby providing new insights for international research in this area.

Further research should also investigate the question of why neighbours matter. Though the discussion above offers some possible explanations, further research is needed to explain the patterns observed in this study. The strong difference between urban and rural areas indicates that structural characteristics might play an important role. Thus further research should try to enrich the analyses by other structural variables and investigate their influence on the clustering processes presented here. Geographic data on urban forms as provided by OpenStreetMap, for example, would offer an interesting extension of socio-demographic characteristics usually used in environmental inequality research. Moreover, combining the spatial patterns of environmental inequality with individual mobility data might offer important insights of the causal mechanisms leading to the disproportionate exposure of minorities to environmental pollution.

\section{References}

Ard, K. (2015). Trends in exposure to industrial air toxins for different racial and socioeconomic groups: A spatial and temporal examination of environmental inequality in the U.S. from 1995 to 2004. Social Science Research, 53, 375-390. doi:.

Ard, K. (2016). By all measures: An examination of the relationship between segregation and health risk from air pollution. Population and Environment, 38, 1-20. doi:.

Ash, M., Boyce, J. K., Chang, G., \& Scharber, H. (2013). Is environmental justice good for white folks? Industrial air toxics exposure in urban America. Social Science Quarterly, 94, 616-636. doi:.

Ash, M., \& Fetter, T. R. (2004). Who lives on the wrong side of the environmental tracks? Evidence from the EPA's risk-screening environmental indicators model. Social Science Quarterly, 85, 441-462. doi:.

Banzhaf, H. S., \& Walsh, R. P. (2008). Do people vote with their feet? An empirical test of Tiebout's mechanism. American Economic Review, 98, 843-863. doi:.

Been, V., \& Gupta, F. (1997). Coming to the nuisance or going to the barrios - a longitudinal analysis of environmental justice claims. Ecology Law Quarterly, 24, 1-56. doi:.

Bivand, R., \& Piras, G. (2015). Comparing implementations of estimation methods for spatial econometrics. Journal of Statistical Software, 63. doi:.

Briggs, D., Abellan, J. J., \& Fecht, D. (2008). Environmental inequity in England: Small area 
associations between socio-economic status and environmental pollution. Social Science $\mathcal{G}$ Medicine, 67, 1612-1629. doi:.

Campbell, H. E., Peck, L. R., \& Tschudi, M. K. (2010). Justice for all? A cross-time analysis of toxics release inventory facility location. Review of Policy Research, 27, 1-25. doi:.

Catney, G. (2016). Exploring a decade of small area ethnic (de-)segregation in England and Wales. Urban Studies, 53, 1691-1709. doi:.

Clark, W. A. V., \& Coulter, R. (2015). Who wants to move? The role of neighbourhood change. Environment and Planning A, 47, 2683-2709. doi:.

Crowder, K., \& Downey, L. (2010). Inter-neighborhood migration, race, and environmental hazards: Modeling micro-level processes of environmental inequality. American Journal of Sociology, 115, 1110-1149. doi:

Crowder, K., Hall, M., \& Tolnay, S. E. (2011). Neighborhood immigration and native outmigration. American Sociological Review, 76, 25-47. doi:

Crowder, K., Pais, J., \& South, S. J. (2012). Neighborhood diversity, metropolitan constraints, and household migration. American Sociological Review, 77, 325-353. doi:.

Diekmann, A., \& Meyer, R. (2010). Demokratischer Smog? Eine empirische Untersuchung zum Zusammenhang zwischen Sozialschicht und Umweltbelastungen. Kölner Zeitschrift für Soziologie und Sozialpsychologie, 62, 437-457. doi:.

Downey, L. (2005). The unintended significance of race: Environmental racial inequality in Detroit. Social Forces, 83, 971-1007. doi:.

Downey, L. (2007). US metropolitan-area variation in environmental inequality outcomes. Urban Studies, 44, 953-977. doi:.

Downey, L., Dubois, S., Hawkins, B., \& Walker, M. (2008). Environmental inequality in metropolitan America. Organization 83 Environment, 21, 270-294. doi:.

Downey, L., \& Hawkins, B. (2008). Race, income, and environmental inequality in the United States. Sociological Perspectives, 51, 759-781. doi:.

Elhorst, J. P. (2014). Spatial Econometrics: From Cross-Sectional Data to Spatial Panels. SpringerBriefs in Regional Science. Berlin, Heidelberg: Springer. doi:.

Elliott, J. R., \& Frickel, S. (2013). The historical nature of cities: A study of urbanization and hazardous waste accumulation. American Sociological Review, 78, 521-543. doi:.

Environmental Protection Agency (2015). EPA's risk-screening environmental indicators (RSEI) methodology. RSEI version 2.3.4. URL: www.epa.gov/sites/production/files/ 2015-12/documents/rsei_methodology_v2.3.4.pdf.

European Commission (2006). Guidance document for the implementation of the European PRTR. URL: http://prtr.ec.europa.eu/docs/en_prtr.pdf.

Farber, S. (1998). Undesirable facilities and property values: A summary of empirical studies. Ecological Economics, 24, 1-14. doi:.

Funderburg, R., \& Laurian, L. (2015). Bolstering environmental (in)justice claims with a quasi-experimental research design. Land Use Policy, 49, 511-526. doi:.

Halleck Vega, S., \& Elhorst, J. P. (2015). The SLX model. Journal of Regional Science, 55, 339-363. doi:.

Hamilton, J. T. (1995). Testing for environmental racism: Prejudice, profits, political power? Journal of Policy Analysis and Management, 14, 107. doi:.

Havard, S., Deguen, S., Zmirou-Navier, D., Schillinger, C., \& Bard, D. (2009). Traffic-related air pollution and socioeconomic status. Epidemiology, 20, 223-230. doi:.

Kabisch, N., \& Haase, D. (2014). Green justice or just green? Provision of urban green spaces in Berlin, Germany. Landscape and Urban Planning, 122, 129-139. doi:.

Kim, Y., Campbell, H., \& Eckerd, A. (2014). Residential choice constraints and environmental justice. Social Science Quarterly, 95, 40-56. doi:.

Kohlhuber, M., Mielck, A., Weiland, S. K., \& Bolte, G. (2006). Social inequality in perceived environmental exposures in relation to housing conditions in Germany. Environmental Research, 101, 246-255. doi:.

Krysan, M., Couper, M. P., Farley, R., \& Forman, T. A. (2009). Does race matter in neighborhood preferences? Results from a video experiment. American Journal of Sociology, 115, 
527-559. doi:.

LeSage, J. P. (2014). What regional scientists need to know about spatial econometrics. The Review of Regional Studies, 44, 13-32.

LeSage, J. P., \& Pace, R. K. (2009). Introduction to Spatial Econometrics. Statistics, Textbooks and Monographs. Boca Raton: CRC Press.

Lichter, D. T., Parisi, D., \& Taquino, M. C. (2015). Toward a new macro-segregation? Decomposing segregation within and between metropolitan cities and suburbs. American Sociological Review, 80, 843-873. doi:.

Mielck, A. (2004). Unterschiede bei Lärmbelastung und Luftverschmutzung nach dem Haushaltseinkommen. In G. Bolte, \& A. Mielck (Eds.), Umweltgerechtigkeit Gesundheitsforschung (pp. 139-154). Weinheim: Juventa-Verl.

Mohai, P., \& Saha, R. (2006). Reassessing racial and socioeconomic disparities in environmental justice research. Demography, 43, 383-399. doi:

Mohai, P., \& Saha, R. (2007). Racial inequality in the distribution of hazardous waste: A national-level reassessment. Social Problems, 54, 343-370. doi:.

Mohai, P., \& Saha, R. (2015a). Which came first, people or pollution? A review of theory and evidence from longitudinal environmental justice studies. Environmental Research Letters, 10, 125011. doi:.

Mohai, P., \& Saha, R. (2015b). Which came first, people or pollution? Assessing the disparate siting and post-siting demographic change hypotheses of environmental injustice. Environmental Research Letters, 10, 115008. doi:.

Oakes, J. M., Anderton, D. L., \& Anderson, A. B. (1996). A longitudinal analysis of environmental equity in communities with hazardous waste facilities. Social Science Research, 25 , 125-148. doi:.

Pace, R. K., \& LeSage, J. P. (2010). Omitted variable biases of ols and spatial lag models. In A. Páez, J. Gallo, R. N. Buliung, \& S. Dall'erba (Eds.), Progress in Spatial Analysis (pp. 17-28). Berlin, Heidelberg: Springer.

Padilla, C. M., Kihal-Talantikite, W., Vieira, V. M., Rossello, P., Le Nir, G., Zmirou-Navier, D., \& Deguen, S. (2014). Air quality and social deprivation in four French metropolitan areas: A localized spatio-temporal environmental inequality analysis. Environmental Research, 134, 315-324. doi:

Pais, J., Crowder, K., \& Downey, L. (2014). Unequal trajectories: Racial and class differences in residential exposure to industrial hazard. Social Forces, 92, 1189-1215. doi:.

Pastor, M., Sadd, J., \& Hipp, J. (2001). Which came first? Toxic facilities, minority move-in, and environmental justice. Journal of Urban Affairs, 23, 1-21. doi:.

Raddatz, L., \& Mennis, J. (2013). Environmental justice in Hamburg, Germany. The Professional Geographer, 65, 495-511. doi:.

Rathelot, R., \& Safi, M. (2014). Local ethnic composition and natives' and immigrants' geographic mobility in France, 1982-1999. American Sociological Review, 79, 43-64. doi:.

Richardson, E. A., Shorty, N. K., \& Mitchell, R. J. (2010). The mechanism behind environmental inequality in Scotland: Which came first, the deprivation or the landfill? Environment and Planning A, 42, 223-240. doi:.

Sager, L. (2012). Residential segregation and socioeconomic neighbourhood sorting: Evidence at the micro-neighbourhood level for migrant groups in Germany. Urban Studies, 49, 26172632. doi:.

Saha, R., \& Mohai, P. (2005). Historical context and hazardous waste facility siting: Understanding temporal patterns in Michigan. Social Problems, 52, 618-648. doi:.

Schelling, T. C. (1978). Micromotives and Macrobehavior. New York: Norton.

Shaikh, S. L., \& Loomis, J. B. (1999). An investigation into the presence and causes of environmental inequity in Denver, Colorado. The Social Science Journal, 36, 77-92. doi:.

Statistische Ämter des Bundes und der Länder (2015). Zensus 2011: Metoden und Berichte. URL: https://www.zensus2011.de/SharedDocs/Downloads/DE/Publikationen/ Aufsaetze_Archiv/2015_06_MethodenUndVerfahren.pdf.

Szasz, A., \& Meuser, M. (2000). Unintended, inexorable: The production of environmental 
inequalities in Santa Clara County, California. American Behavioral Scientist, 43, 602-632. doi:.

Ward, M. D., \& Gleditsch, K. S. (2008). Spatial Regression Models volume 155 of Quantitative Applications in the Social Sciences. Thousand Oaks: Sage Publications.

Wolverton, A. (2009). Effects of socio-economic and input-related factors on polluting plants' location decisions. The B.E. Journal of Economic Analysis \&5 Policy, 9. doi:.

Wolverton, A. (2012). The role of demographic and cost-related factors in determining where plants locate: A tale of two teas cities. In H. S. Banzhaf (Ed.), The Political Economy of Environmental Justice (pp. 199-222). Palo Alto: Stanford University Press. 

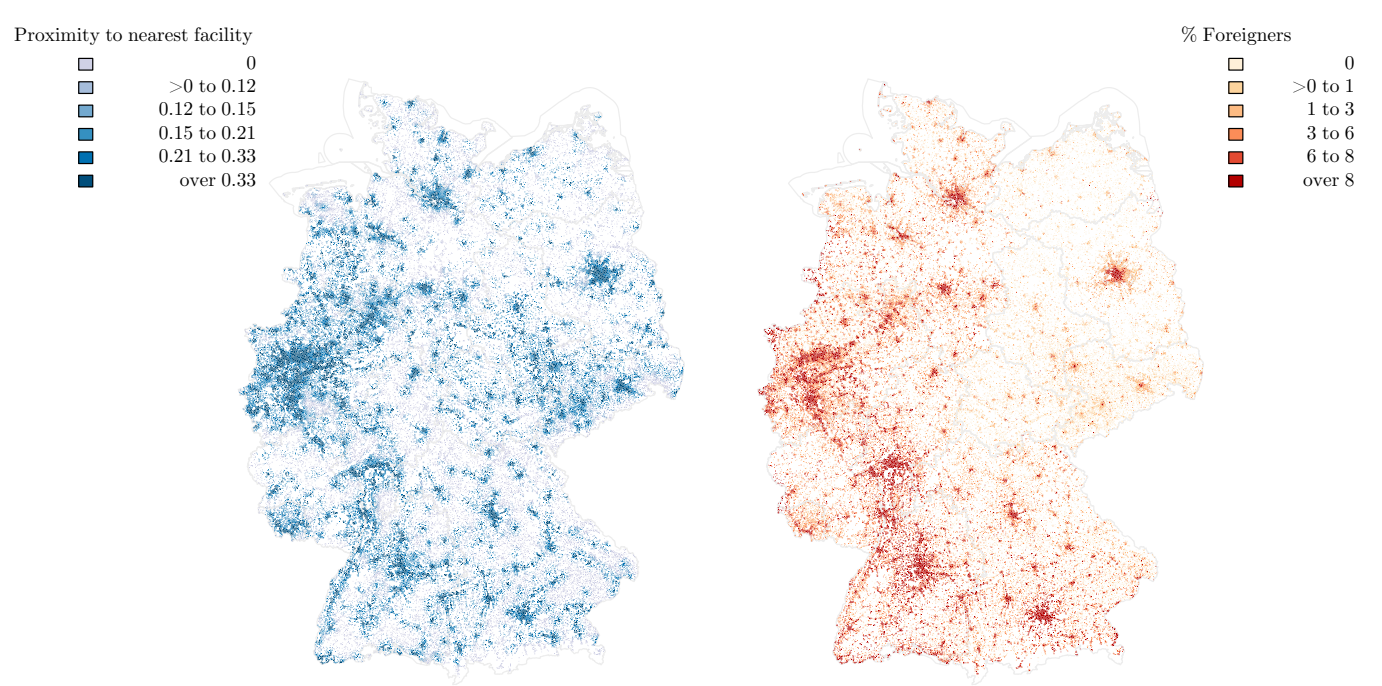

Figure A1. Spatial distribution of roximity to nearest facility and minority share in Germany

\section{Appendix A. Proximity to nearest Facility}
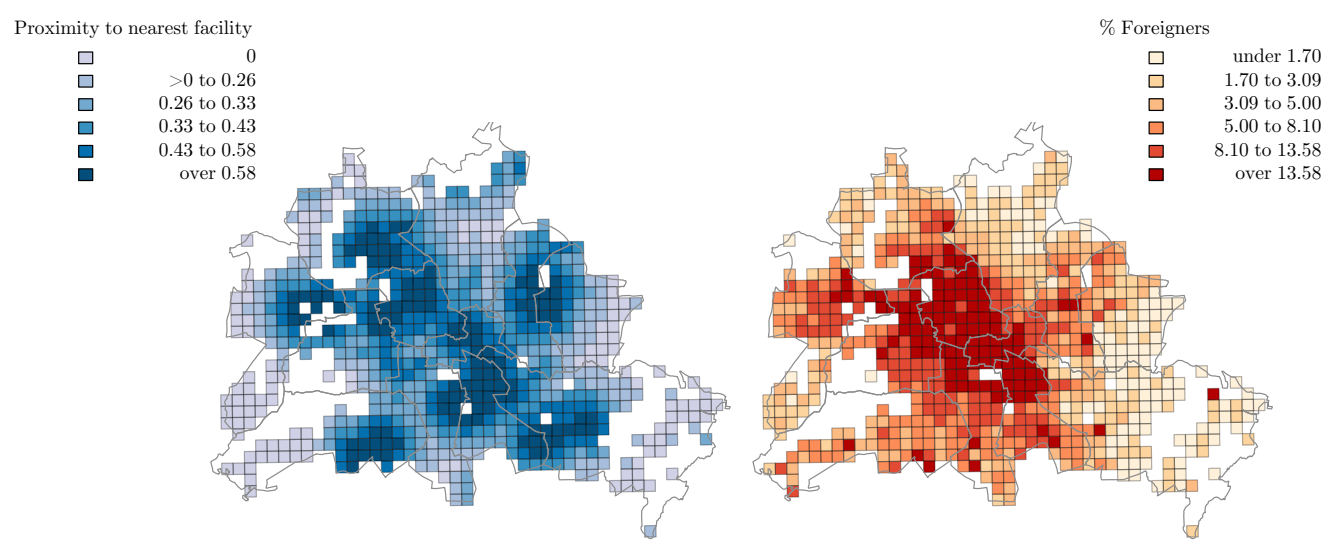

Figure A2. Spatial distribution of proximity to nearest facility and minority share in Berlin 
Table A1. OLS and SLX estimates. Dependent variable: proximity to nearest facility

\begin{tabular}{|c|c|c|c|c|}
\hline & OLS & & SLX & \\
\hline & M1 & M2 & M3 & M4 \\
\hline (Intercept) & $\begin{array}{c}0.000 \\
(0.003)\end{array}$ & $\begin{array}{c}-0.007^{*} \\
(0.003)\end{array}$ & $\begin{array}{c}-0.049^{* * *} \\
(0.003)\end{array}$ & $\begin{array}{c}-0.025^{* * *} \\
(0.003)\end{array}$ \\
\hline$\%$ Foreigners & $\begin{array}{l}0.320^{* * *} \\
(0.003)\end{array}$ & $\begin{array}{l}0.155^{* * *} \\
(0.004)\end{array}$ & $\begin{array}{l}0.119^{* * *} \\
(0.004)\end{array}$ & $\begin{array}{l}0.076^{* * *} \\
(0.005)\end{array}$ \\
\hline $\mathrm{W}$ [\% Foreigners] & & $\begin{array}{l}0.282^{* * *} \\
(0.005)\end{array}$ & $\begin{array}{l}0.165^{* * *} \\
(0.006)\end{array}$ & $\begin{array}{l}0.089^{* * *} \\
(0.006)\end{array}$ \\
\hline Population & & & $\begin{array}{c}-0.035^{* * *} \\
(0.005)\end{array}$ & $\begin{array}{l}0.061^{* * *} \\
(0.006)\end{array}$ \\
\hline W [Population] & & & $\begin{array}{l}0.180^{* * *} \\
(0.007)\end{array}$ & $\begin{array}{l}0.372^{* * *} \\
(0.009)\end{array}$ \\
\hline$\% 65$ and older & & & $\begin{array}{l}0.014^{* * *} \\
(0.003)\end{array}$ & $\begin{array}{c}0.005 \\
(0.003)\end{array}$ \\
\hline $\mathrm{W}$ [\% 65 and older] & & & $\begin{array}{l}0.021^{* * *} \\
(0.004)\end{array}$ & $\begin{array}{c}0.004 \\
(0.004)\end{array}$ \\
\hline$\%$ Vacant housing & & & $\begin{array}{l}0.016^{* * *} \\
(0.003)\end{array}$ & $\begin{array}{c}0.006 \\
(0.003)\end{array}$ \\
\hline W [\% Vacant housing] & & & $\begin{array}{c}0.004 \\
(0.004)\end{array}$ & $\begin{array}{c}-0.012^{* *} \\
(0.004)\end{array}$ \\
\hline Living space & & & $\begin{array}{c}-0.039^{* * *} \\
(0.003)\end{array}$ & $\begin{array}{c}-0.025^{* * *} \\
(0.003)\end{array}$ \\
\hline $\mathrm{W}$ [Living space] & & & $\begin{array}{c}-0.069^{* * *} \\
(0.004)\end{array}$ & $\begin{array}{c}-0.046^{* * *} \\
(0.004)\end{array}$ \\
\hline Urban & & & $\begin{array}{l}0.378^{* * *} \\
(0.012)\end{array}$ & $\begin{array}{l}0.459^{* * *} \\
(0.015)\end{array}$ \\
\hline Urban $\times \%$ Foreigners & & & & $\begin{array}{l}0.070^{* * *} \\
(0.012)\end{array}$ \\
\hline Urban $\times \mathrm{W}[\%$ Foreigners $]$ & & & & $\begin{array}{l}0.142^{* * *} \\
(0.016)\end{array}$ \\
\hline$R^{2}$ & 0.103 & 0.131 & 0.173 & 0.193 \\
\hline Adj. $R^{2}$ & 0.102 & 0.131 & 0.173 & 0.193 \\
\hline $\mathrm{N}$ & 93777 & 93777 & 93777 & 93777 \\
\hline
\end{tabular}

${ }^{* * *} p<0.001,{ }^{* *} p<0.01,{ }^{*} p<0.05$. Standardised coefficients. Standard errors in parentheses. W is specified as contiguity neighbours weights matrix. Model M4 interacts all covariates with the urban dummy (interaction with controls not shown). 
Table A2. Community-fixed effects estimates. Dependent variable: proximity to nearest facility

\begin{tabular}{|c|c|c|c|c|}
\hline & Overall & Urban & Rural & Diff \\
\hline & M5 & M6 & M7 & (M6-M7) \\
\hline \multirow[t]{2}{*}{$\%$ Foreigners } & $0.132^{* * *}$ & $0.153^{* * *}$ & $0.088^{* * *}$ & $0.065^{*}$ \\
\hline & $(0.009)$ & $(0.025)$ & $(0.008)$ & $(0.027)$ \\
\hline \multirow[t]{2}{*}{$\mathrm{W}$ [\% Foreigners] } & $0.216^{* * *}$ & $0.357^{* * *}$ & $0.122^{* * *}$ & $0.236^{* * *}$ \\
\hline & $(0.018)$ & $(0.036)$ & $(0.013)$ & $(0.038)$ \\
\hline \multirow[t]{2}{*}{ Population } & $-0.044^{* * *}$ & $-0.086^{* * *}$ & $0.017^{*}$ & $-0.102^{* * *}$ \\
\hline & $(0.009)$ & $(0.010)$ & $(0.007)$ & $(0.012)$ \\
\hline \multirow{2}{*}{$\mathrm{W}$ [Population] } & $0.079^{* * *}$ & -0.013 & $0.169^{* * *}$ & $-0.182^{* * *}$ \\
\hline & $(0.013)$ & $(0.024)$ & $(0.016)$ & $(0.029)$ \\
\hline \multirow[t]{2}{*}{$\% 65$ and older } & 0.005 & -0.011 & 0.004 & -0.015 \\
\hline & $(0.002)$ & $(0.012)$ & $(0.002)$ & $(0.012)$ \\
\hline \multirow[t]{2}{*}{$\mathrm{W}[\% 65$ and older $]$} & 0.007 & 0.018 & 0.006 & 0.012 \\
\hline & $(0.004)$ & $(0.044)$ & $(0.004)$ & $(0.045)$ \\
\hline \multirow[t]{2}{*}{$\%$ Vacant housing } & $0.017^{* * *}$ & $0.035^{*}$ & $0.011^{* * *}$ & 0.024 \\
\hline & $(0.003)$ & $(0.017)$ & $(0.003)$ & $(0.017)$ \\
\hline \multirow[t]{2}{*}{$\mathrm{W}[\%$ Vacant housing $]$} & 0.009 & 0.036 & 0.003 & 0.033 \\
\hline & $(0.005)$ & $(0.053)$ & $(0.005)$ & $(0.054)$ \\
\hline \multirow[t]{2}{*}{ Living space } & $-0.035^{* * *}$ & $-0.086^{* * *}$ & $-0.018^{* * *}$ & $-0.067^{* *}$ \\
\hline & $(0.004)$ & $(0.023)$ & $(0.003)$ & $(0.023)$ \\
\hline \multirow[t]{2}{*}{$\mathrm{W}$ [Living space] } & $-0.063^{* * *}$ & $-0.358^{* * *}$ & $-0.032^{* * *}$ & $-0.325^{* * *}$ \\
\hline & $(0.007)$ & $(0.052)$ & $(0.004)$ & $(0.053)$ \\
\hline$R^{2}$ & 0.069 & 0.167 & 0.044 & \\
\hline Adj. $R^{2}$ & 0.066 & 0.166 & 0.042 & \\
\hline $\mathrm{N}$ & 93777 & 9061 & 84716 & \\
\hline
\end{tabular}

${ }^{* * *} p<0.001,{ }^{* *} p<0.01,{ }^{*} p<0.05$. Standardised coefficients. Cluster robust standard errors in parentheses. $\mathrm{W}$ is specified as contiguity neighbours weights matrix. The differences and standard errors in column 4 are obtained by an overall fixed-effects model with interaction terms of the urban dummy and all covariates. 